\title{
Threat, Coping, and Social Distance Adherence During COVID-19: Cross-Continental Comparison Using an Online Cross-Sectional Survey
}

Abrar Al-Hasan ${ }^{1}$, BSc, MBA, PhD; Jiban Khuntia ${ }^{2}$, ME, PhD; Dobin Yim², BS, MS, MBA, MA, PhD

${ }_{1}^{1}$ Kuwait University, AlShadadiya University City, Kuwait
${ }^{2}$ University of Colorado Denver, Denver, CO, United States
${ }^{3}$ Loyola University Maryland, Baltimore, MD, United States

Corresponding Author:

Abrar Al-Hasan, BSc, MBA, PhD

Kuwait University

College of Business Administration

AlShadadiya University City, 13055

Kuwait

Phone: 96551165005

Email: abrar.alhasan@ku.edu.kw

\section{Abstract}

Background: Social distancing is an effective preventative policy for COVID-19 that is enforced by governments worldwide. However, significant variations are observed in adherence to social distancing across individuals and countries. Due to the lack of treatment, rapid spread, and prevalence of COVID-19, panic and fear associated with the disease causes great stress. Subsequent effects will be a variation around the coping and mitigation strategies for different individuals following different paths to manage the situation.

Objective: This study aims to explore how threat and coping appraisal processes work as mechanisms between information and citizens' adherence to COVID-19-related recommendations (ie, how the information sources and social media influence threat and coping appraisal processes with COVID-19 and how the threat and coping appraisal processes influence adherence to policy guidelines). In addition, this study aims to explore how citizens in three different countries (the United States, Kuwait, and South Korea), randomly sampled, are effectively using the mechanisms.

Methods: Randomly sampled online survey data collected by a global firm in May 2020 from 162 citizens of the United States, 185 of Kuwait, and 71 of South Korea were analyzed, resulting in a total sample size of 418. A seemingly unrelated regression model, controlling for several counterfactuals, was used for analysis. The study's focal estimated effects were compared across the three countries using the weighted distance between the parameter estimates.

Results: The seemingly unrelated regression model estimation results suggested that, overall, the intensity of information source use for the COVID-19 pandemic positively influenced the threat appraisal for the disease $(P<.001)$. Furthermore, the intensity of social media use for the COVID-19 pandemic positively influenced the coping appraisal for the disease $(P<.001)$. Higher COVID-19 threat appraisal had a positive effect on social distancing adherence $(P<.001)$. Higher COVID-19 coping appraisal had a positive effect on social distancing adherence $(P<.001)$. Higher intensity of COVID-19 knowledge positively influenced social distancing adherence $(P<.001)$. There were country-level variations. Broadly, we found that the United States had better results than South Korea and Kuwait in leveraging the information to threat and coping appraisal to the adherence process, indicating that individuals in countries like the United States and South Korea may be more pragmatic to appraise the situation before making any decisions.

Conclusions: This study's findings suggest that the mediation of threat and coping strategies are essential, in varying effects, to shape the information and social media strategies for adherence outcomes. Accordingly, coordinating public service announcements along with information source outlets such as mainstream media (eg, TV and newspaper) as well as social media (eg, Facebook and Twitter) to inform citizens and, at the same time, deliver balanced messages about the threat and coping appraisal is critical in implementing a staggered social distancing and sheltering strategy. 


\section{KEYWORDS}

COVID-19; adherence; coping appraisal; threat appraisal; protection motivation theory; social distancing; information sources; social media; knowledge; coping; threat; protection; motivation; cross-sectional; survey

\section{Introduction}

COVID-19 has instilled fear among all individuals across the world. Since beginning in Wuhan, China in December 2019, the COVID-19 pandemic has led to more than 6.5 million cases and 390,000 deaths reported worldwide as of June 4, 2020 [1].

Although there is no treatment or vaccine for COVID-19 [2] yet, the mitigation approach to COVID-19 has focused on infection control, effective quarantine, and treatment cure rates $[3,4]$. Infected individuals do not often exhibit any symptoms, and the disease progresses swiftly and kills patients at a much higher rate than the typical flu [5]. Limited testing availability, combined with few treatment options other than a ventilator to assist breathing, forces individuals to adopt a varying level of preventive measures [6-9], including measures to help alleviate psychological impacts [10,11].

Individuals can practice good respiratory hygiene by washing hands with soap and water often for at least 20 seconds and avoiding touching the eyes, nose, or mouth with unwashed hands. More drastic efforts include social distancing or maintaining a safe distance from others and sheltering practices by staying at home to avoid all contacts [2].

There are variations in citizens' adherence to the COVID-19-related social distancing guidelines suggested by governments across countries to manage and mitigate the disease, aligning to the preventive measures [12], for example, whether or not to wear a mask $[13,14]$. Citizen's willingness to follow the guidance will depend on the fear and anxiety caused by the disease. Arguably, compared to other diseases, infectious diseases like COVID-19 induce fear because of known and unknown reasons associated with spread and prevalence, the high rates of morbidity and mortality, and subsequent societal stigma and discrimination associated with the diagnosis and treatment of the disease [15-18].

Along with the actual nature and impact of COVID-19, the information available through different channels and the discussions through social media have played a significant role in influencing people's mindsets. The COVID-19 pandemic is associated with sleep disturbance and suicidal thoughts [19], misinformation and distress [20,21], and greater self-confidence when receiving information from more sources but only for health care workers [22]. Thus, the culmination of information and social media influences can influence the fear and coping strategies related to the disease and subsequent adherence to the policy recommendations [23].

The panic and fear associated with the disease will create a struggle in people's mindsets, including creating worst-case scenarios around their situations [24]. Subsequent effects will be a variation around the coping and mitigation strategies for different individuals following different paths to manage the situation.
In this context, this study asks two research questions: (1) How do the information sources and social media influence the threat and coping appraisal process with COVID-19? and (2) How does the threat and coping appraisal process influences adherence to policy guidelines?

The COVID-19 situation poses a sense of helplessness in that there is no treatment, and thus, individuals rely on different information sources to learn about the disease. Because they cannot see a doctor as a preassessment or plan for the disease, the information gained from the press, television, and internet influences their disease management and mitigation strategy. Thus, individual behavior would be affected by these information sources, as individuals will try to understand and maneuver complex situations [25-28]. Furthermore, given that social media is emerging as a critical information source to influence individual beliefs and perceptions, it is beyond doubt that such an influence would be quite useful in the COVID-19 situation [29-31].

Threat and coping appraisal mechanisms, grounded in the protection motivation theory (PMT), have been suggested to be precursors of individuals' actions to protect against infectious diseases [32] such as the influenza outbreak [33]. The intention to adopt a protective behavior such as adhering to the social distance recommendations results from perceiving a given threat such as a disease and desiring to avoid the adverse outcomes of such a threat [34]. The protection motivation perspective suggests that health risk is appraised by considering what the threat is because of the severity of a disease or health issue (threat appraisal: severity), how vulnerable an individual perceives the disease or health issue (threat appraisal: vulnerability), how successful preventative behavior is (coping appraisal: response efficacy), and how confident the individual feels in preventing the risk (coping appraisal: self-efficacy). Although several extensions and applications of the protection motivation concept are applied to health contexts, the basic premise of threat appraisal, consisting of severity and vulnerability, and coping appraisal, consisting of self and response efficacies, have remained similar (for a meta-analysis, see $[34,35])$.

Taking a closer look at people's actions, thoughts, or emotions can be a complicated process. However, resisting or suppressing our emotions creates paradoxical outcomes such as aggravating our fears instead of making them vanish. Thus, these coping strategies embrace and approach our stressors head-on to build grit and resilience. It is normal to find it challenging to be consistent when starting a new routine. In this context, exploration of COVID-19 mitigation using threat and coping appraisal mechanisms is essential.

Based on these discussions, this study focuses explicitly on testing the following hypotheses: 
1. The intensity of the use of information sources for COVID-19 positively influences the threat appraisal for the disease.

2. The intensity of social media use for COVID-19 positively influences the coping appraisal for the disease.

3. A higher COVID-19 threat appraisal positively influences citizens' adherence intentions.

4. A higher COVID-19 coping appraisal positively influences citizens' adherence intentions.

This study conducts a comparative evaluation of the citizens' adherence process to COVID-19-related recommendations by the governments in three different countries: the United States, Kuwait, and South Korea.

\section{Methods}

\section{Recruitment}

This study started with a discussion in a focus group in Kuwait. The ten people who participated in the focus group opined that assessing threat and coping strategies is essential to manage the COVID-19 situation. Along with this insight, the group also suggested that different cultural systems and relevant mindsets will differ in adhering to government recommendations. This motivated us to study the research question across different countries with polarized mindsets and different cultural systems. Thus, the study expanded to other countries with different cultures. Due to resource constraints, the sampling was limited to countries that the authors have firsthand experience in explaining the similarities and differences.

A global survey-deploying firm collected the data for this study using online platforms. The firm recruited respondents from the United States, Kuwait, and South Korea in May 2020. The firm sampled respondents using an age, gender, ethnicity, and geographic region-based strata and quota matching process. Participation in the survey was free and voluntary; the respondents filled in electronic informed consent that was shown on the first page of the survey. The firm protects the confidentiality of anonymous respondents.

\section{Data Collection}

Data was collected using a survey instrument, as shown in Multimedia Appendix 1 Table A1. The questions asked participants about the cause and current state of the COVID-19 situation, their opinion on the government's role during the COVID-19 pandemic, the use of health information sources and social media for COVID-19-related information, and PMT measures for the COVID-19 pandemic adapted from previously validated scales [36-39]. The survey items included simple information-seeking questions and several existing validated scales from prior studies [35,40-47].

The survey instrument was pilot-tested using a sample of 48 respondents, leading to minor refinements to a few items. A total of 482 participants took the survey. Because of missing responses to the items, 64 observations were excluded, resulting in a sample size of 418. Responses were coded, validated, and analyzed using Stata version 16 (StataCorp).

\section{Sample Demographics}

Table 1 shows the descriptive statistics and pairwise correlations among the key variables used in this study. Out of 418 participants, $299(58.7 \%)$ were female. The sample's largest age group was $18-27$ years $(n=192,37.3 \%)$. This group was followed by the 28-37 years age group $(n=150,29.1 \%), 38-47$ years age group $(n=70,13.6 \%), 48-57$ years age group $(n=43$, $8.4 \%)$, and 58 years or older group $(n=60,11.7 \%)$. Multimedia Appendix 1 Figure A1 shows the countrywise comparison of the respondents' age. In terms of income level, $102(20.5 \%)$ participants make less than US $\$ 30,000$ annually; 92 (18.5\%) make US \$30,000-US \$50,000; 102 (20.5\%) make US $\$ 50,000-$ US $\$ 80,000 ; 65(13.1 \%)$ make US $\$ 80,000-$ US $\$ 100,000 ; 57$ (11.5\%) make US \$100,000-US \$150,000; and $79(15.9 \%)$ make more than US $\$ 150,000$. The household income distribution as varied by country is shown in Multimedia Appendix 1 Figure A2. A detailed distribution of several demographic controls used in the models is available in Multimedia Appendix 1 Table A2. 
Table 1. Summary statistics and pairwise correlations among key variables $(\mathrm{N}=418)$.

\begin{tabular}{|c|c|c|c|c|c|c|c|c|c|c|c|c|c|c|c|c|}
\hline Variabless & Mean (SD) & Min & Max & 1 & 2 & 3 & 4 & 5 & 6 & 7 & 8 & 9 & 10 & 11 & 12 & 13 \\
\hline Adherence (1) & $4.18(1.00)$ & 1 & 5 & 1.00 & & & & & & & & & & & & \\
\hline Threat appraisal (2) & $3.32(0.87)$ & 1 & 5 & 0.38 & 1.00 & & & & & & & & & & & \\
\hline Severity (3) & $3.55(0.97)$ & 1 & 5 & 0.45 & 0.87 & 1.00 & & & & & & & & & & \\
\hline Vulnerability (4) & $3.10(1.01)$ & 1 & 5 & 0.21 & 0.89 & 0.55 & 1.00 & & & & & & & & & \\
\hline Coping appraisal (5) & $2.93(0.78)$ & 1 & 5 & 0.53 & 0.44 & 0.46 & 0.32 & 1.00 & & & & & & & & \\
\hline Self-efficacy (6) & $3.06(1.51)$ & 1 & 5 & 0.28 & 0.31 & 0.30 & 0.25 & 0.84 & 1.00 & & & & & & & \\
\hline Response efficacy (7) & $4.29(0.89)$ & 1 & 5 & 0.64 & 0.42 & 0.46 & 0.27 & 0.77 & 0.30 & 1.00 & & & & & & \\
\hline Knowledge (8) & $15.04(3.62)$ & 4 & 24 & 0.33 & 0.10 & 0.18 & 0.01 & 0.33 & 0.17 & 0.39 & 1.00 & & & & & \\
\hline Information source (9) & $2.26(1.25)$ & 0 & 5 & 0.16 & 0.08 & 0.08 & 0.05 & 0.17 & 0.04 & 0.27 & 0.19 & 1.00 & & & & \\
\hline Social media (10) & $1.65(1.43)$ & 0 & 7 & 0.03 & 0.17 & 0.17 & 0.12 & 0.08 & 0.13 & 0.00 & 0.02 & 0.40 & 1.00 & & & \\
\hline Age (11) & $2.27(1.35)$ & 1 & 5 & 0.00 & 0.00 & 0.03 & -0.03 & 0.00 & -0.10 & 0.12 & 0.09 & 0.21 & 0.04 & 1.00 & & \\
\hline Female (12) & $0.59(0.49)$ & 0 & 1 & 0.11 & 0.11 & 0.09 & 0.11 & 0.15 & 0.17 & 0.07 & 0.13 & 0.09 & 0.08 & 0.00 & 1.00 & \\
\hline Household income (13) & $2.24(1.72)$ & 0 & 5 & 0.05 & -0.07 & -0.03 & -0.09 & 0.13 & 0.14 & 0.06 & 0.11 & 0.04 & -0.04 & 0.04 & -0.12 & 1.00 \\
\hline
\end{tabular}

\section{Study Variables}

The main dependent variable in this study is adherence. As shown in Multimedia Appendix 1 Table A1, adherence was measured using three questions of whether they would comply with the social distancing measures. The items' internal consistencies were tested using Cronbach alpha (0.81), and the standardized score was generated for the adherence variable. Table 1 shows that, on average, adherence is 4.18 out of 5 , showing that most people are adhering to social distancing recommendations. The mean adherence level in Kuwait was the highest (mean 4.53, SD 0.81), followed by the United States (mean 4.14, SD 0.92) and South Korea (mean 3.53, SD 1.18). Multimedia Appendix 1 Figure A3 displays the mean adherence across countries.

Three main independent variables were of interest in this study to examine adherence. First, the independent variable threat appraisal consists of both the severity and vulnerability of the situation [46]. Severity is the perceived degree of harm from engaging in unhealthy behavior, the extent to which one will experience or die from contracting COVID-19 upon not following social distancing recommendations. Vulnerability is the perceived probability of threat occurrence, the extent to which one will contract COVID-19 upon not following social distancing recommendations. Both variables were operationalized using three questions adopted from previous studies to assess the severity and vulnerability of the COVID-19 pandemic (see Multimedia Appendix 1 Table A1). The items' internal consistency was tested using Cronbach alpha ( 0.63 and 0.76 , respectively), and the standardized score was generated for both severity and vulnerability variables.

The second main independent variable was coping appraisal, which consists of both self-efficacy and response efficacy of the situation [46]. Self-efficacy is the perceived belief that one can successfully maintain a safe distance from others when in contact or stay home to avoid all contacts. Response efficacy is the perceived efficacy of adherence that adopting social distancing will be effective in reducing the threat of COVID-19.
Both variables were operationalized using three questions adopted from previous studies to assess the self-efficacy and response efficacy of adherence to the COVID-19 pandemic regulations (see Multimedia Appendix 1 Table A1). The items' internal consistency was tested using Cronbach alpha ( 0.6 and 0.8 , respectively), and the standardized score was generated for both self-efficacy and response efficacy variables.

Lastly, the knowledge variable was coded to reflect the respondents' overall knowledge of COVID-19, as displayed in Multimedia Appendix 1 Table A1. The mean for knowledge was 15.04 , with a minimum of 4 and a maximum of 24 . The mean COVID-19 knowledge was highest in Kuwait (mean 16.32, SD 3.05), followed by the United States (mean 15.04, SD 3.62) and South Korea (mean 11.85, SD 3.74). Multimedia Appendix 1 Figure A4 displays the mean knowledge across countries.

To examine threat appraisal and coping appraisal, this study focuses on COVID-19 information sources used and on COVID-19 social media use. COVID-19 information sources was operationalized as the total number of sources used to attain COVID-19 health information. Table 1 displays the mean for the whole sample as 2.26 , showing that individuals use two information sources on average to attain COVID-19 information. The mean was highest in Kuwait (mean 2.50, SD 1.13), followed by the United States (mean 2.31, SD 1.34), and South Korea (mean 1.68, SD 1.11). COVID-19 social media was also operationalized as the total number of social media platforms used to attain COVID-19 health information. Table 1 displays the mean for the whole sample as 1.16, showing that individuals use one social media platform to attain COVID-19 information. The mean was highest in Kuwait (mean 2.10, SD 1.38), followed by South Korea (mean 1.48, SD 1.36) and the United States (mean 1.29, SD 1.41). COVID-19 social media was further examined by categorizing the platforms to social network platforms (Facebook and LinkedIn), media sharing platforms (Instagram, Snapchat, TikTok, and YouTube), and texting and microblogging platforms (Twitter and Whatsapp). Details of the analysis are shown in Multimedia Appendix 1 Table A5. 
In addition to these key variables of interest, several control variables such as age, gender, and household income were included to account for counterfactual explanations relevant to our models (see Multimedia Appendix 1 Table A1 for details).

\section{Econometric Analysis}

Following PMT, the empirical model specifies how individuals express their opinion toward adherence of social distancing guidance by the government through threat appraisal, coping appraisal, and knowledge of COVID-19. Furthermore, threat appraisal and coping appraisal were specified through COVID-19 sources of information (COVID-19 information sources and COVID-19 social media). A set of control variables to enhance our empirical model's robustness included demographics characteristics of the survey participants, such as gender, age, and household income. The formal specification of the general model is as follows:

Threat appraisal model:

Threat appraisal $_{i}=\beta_{0}+\beta_{1} \times$ COVID-19 information sources $_{i}+\beta_{2} \times$ COVID-19 social media $i+\beta_{3} \times$ Country + Controls $_{i}+i \mathbf{( 1 )}$

Coping appraisal model:

Coping appraisal ${ }_{i}=\beta_{0}+\beta_{1} \times$ COVID-19 information sources $_{i}+\beta_{2} \times$ COVID-19 social media $i+\beta_{3} \times$ Country + Controls $_{i}+i(\mathbf{2})$

Adherence model:

Adherence $_{i}=\beta_{0}+\beta_{1} \times$ Threat appraisal_hat ${ }_{i}+\beta_{2}$ $\times$ Coping appraisal_hat ${ }_{i}+\beta_{3} \times$ Knowledge $_{i}+\beta_{4} \times$ Country + Controls $_{i}+i(\mathbf{3})$
Where controls includes gender, age groups, and household income. The country dummy was included in the full sample model but was removed for subsample analyses.

Seemingly unrelated regression (SUR) was used to estimate the $\beta$ coefficients of the key parameters and employ robust standard errors to test the models. are the disturbances associated with each observation. SUR was used to estimate to what extent our set of key variables influence adherence. The adherence model (Equation 3) uses the predicted values of threat appraisal (threat appraisal_hat) and coping appraisal (coping appraisal_hat) from the first stage models (Equations 1 and 2).

\section{Results}

Table 2 presents the key estimation results for Equations 1-3 for the whole sample. The first column (1) in the table shows the parameter estimates for the coping appraisal dependent variable, column (2) shows the parameter estimates for the threat appraisal dependent variable, and column (3) shows the parameter estimates for the adherence dependent variable for the full sample. Table 3 displays the key estimation results for Equations 1 and 2 for the individual countries. Columns 1-3 show the parameter estimates for the coping appraisal dependent variable, and columns 4-6 display the parameter estimates for the threat appraisal dependent variable for the United States, South Korea, and Kuwait, respectively. Table 4 presents the key estimation results for the adherence dependent variable, as in Equation 3, for the United States, South Korea, and Kuwait. Multimedia Appendix 1 Table A3 further analyzes the adherence model using the constituent variables (severity, vulnerability, self-efficacy, and response efficacy). 
Table 2. Seemingly unrelated regression model results for the full sample.

\begin{tabular}{|c|c|c|c|c|c|c|}
\hline \multirow[t]{2}{*}{ Variables } & \multicolumn{2}{|c|}{$\mathrm{DV}^{\mathrm{a}}$ : coping appraisal (1) } & \multicolumn{2}{|c|}{ DV: threat appraisal (2) } & \multicolumn{2}{|c|}{ DV: adherence (3) } \\
\hline & Full sample & $P$ value & Full sample & $P$ value & Full sample & $P$ value \\
\hline COVID-19 information source & $0.112(0.03)^{\mathrm{b}}$ & $<.001$ & $0.034(0.04)$ & .35 & $\mathrm{~N} / \mathrm{A}^{\mathrm{c}}$ & N/A \\
\hline COVID-19 social media & $0.034(0.03)$ & .35 & $0.112(0.03)$ & $<.001$ & N/A & N/A \\
\hline Threat appraisal & N/A & N/A & N/A & N/A & $0.215(0.05)$ & $<.001$ \\
\hline Coping appraisal & N/A & N/A & $\mathrm{N} / \mathrm{A}$ & N/A & $0.511(0.06)$ & $<.001$ \\
\hline Knowledge & $\mathrm{N} / \mathrm{A}$ & N/A & N/A & N/A & $0.061(0.01)$ & $<.001$ \\
\hline Age & $-0.008(0.03)$ & .72 & $0.011(0.03)$ & .72 & $0.006(0.03)$ & .85 \\
\hline Female & $0.213(0.08)$ & .04 & $0.174(0.09)$ & .04 & $0.038(0.08)$ & .64 \\
\hline Household income & $0.055(0.02)$ & .15 & $-0.037(0.03)$ & .15 & $-0.002(0.02)$ & .94 \\
\hline Constant & $2.328(0.13)$ & $<.001$ & $2.936(0.15)$ & $<.001$ & $1.034(0.23)$ & $<.001$ \\
\hline Observations, $\mathrm{n}$ & 418 & $\mathrm{~N} / \mathrm{A}$ & 418 & N/A & 418 & N/A \\
\hline$R^{2}$ & 0.076 & N/A & 0.051 & N/A & 0.375 & N/A \\
\hline Chi-square & 34.25 & N/A & 22.37 & N/A & 249.90 & N/A \\
\hline Root mean square error & 0.7482 & N/A & 0.8420 & N/A & N/A & N/A \\
\hline$P$ value & N/A & $<.001$ & N/A & $<.001$ & N/A & $<.001$ \\
\hline
\end{tabular}

${ }^{\mathrm{a} D V}$ : dependent variable.

${ }^{\mathrm{b}}$ Standard errors in parentheses.

${ }^{\mathrm{c}} \mathrm{N} / \mathrm{A}$ : not applicable. 
Table 3. Coping and threat appraisal seemingly unrelated regression model results for individual countries.

\begin{tabular}{|c|c|c|c|c|c|c|c|c|c|c|c|c|}
\hline \multirow[t]{2}{*}{ Variables } & \multicolumn{6}{|c|}{$\mathrm{DV}^{\mathrm{a}}$ : coping appraisal } & \multicolumn{6}{|c|}{ DV: threat appraisal } \\
\hline & US (1) & $P$ value & $\begin{array}{l}\text { South Ko- } \\
\text { rea }(2)\end{array}$ & $P$ value & $\begin{array}{l}\text { Kuwait } \\
\text { (3) }\end{array}$ & $P$ value & US (4) & $P$ value & $\begin{array}{l}\text { South Ko- } \\
\text { rea }(5)\end{array}$ & $P$ value & $\begin{array}{l}\text { Kuwait } \\
\text { (6) }\end{array}$ & $P$ value \\
\hline $\begin{array}{l}\text { COVID-19 in- } \\
\text { formation } \\
\text { source }\end{array}$ & $\begin{array}{l}0.099 \\
(0.04)^{b}\end{array}$ & .01 & $\begin{array}{l}0.221 \\
(0.08)\end{array}$ & .007 & $\begin{array}{l}0.053 \\
(0.04)\end{array}$ & $\mathrm{N} / \mathrm{A}^{\mathrm{c}}$ & $\begin{array}{l}0.021 \\
(0.05)\end{array}$ & .68 & $\begin{array}{l}0.213 \\
(0.12)\end{array}$ & .07 & $\begin{array}{l}0.077 \\
(0.05)\end{array}$ & .11 \\
\hline $\begin{array}{l}\text { COVID-19 so- } \\
\text { cial media }\end{array}$ & $\begin{array}{l}-0.007 \\
(0.04)\end{array}$ & .86 & $\begin{array}{l}-0.029 \\
(0.08)\end{array}$ & .71 & $\begin{array}{l}-0.009 \\
(0.03)\end{array}$ & N/A & $\begin{array}{l}0.173 \\
(0.05)\end{array}$ & $<.001$ & $\begin{array}{l}-0.122 \\
(0.11)\end{array}$ & .28 & $\begin{array}{l}0.011 \\
(0.04)\end{array}$ & .77 \\
\hline Age & $\begin{array}{l}-0.0908 \\
(0.04)\end{array}$ & .01 & $\begin{array}{l}-0.002 \\
(0.08)\end{array}$ & .98 & $\begin{array}{l}0.045 \\
(0.03)\end{array}$ & N/A & $\begin{array}{l}-0.043 \\
(0.05)\end{array}$ & .35 & $\begin{array}{l}0.040 \\
(0.11)\end{array}$ & .72 & $\begin{array}{l}0.052 \\
(0.04)\end{array}$ & .19 \\
\hline Female & $\begin{array}{l}0.032 \\
(0.11)\end{array}$ & .76 & $\begin{array}{l}0.058 \\
(0.18)\end{array}$ & .75 & $\begin{array}{l}0.095 \\
(0.08)\end{array}$ & N/A & $\begin{array}{l}0.065 \\
(0.14)\end{array}$ & .63 & $\begin{array}{l}-0.122 \\
(0.26)\end{array}$ & .63 & $\begin{array}{l}0.246 \\
(0.10)\end{array}$ & .02 \\
\hline $\begin{array}{l}\text { Household in- } \\
\text { come }\end{array}$ & $\begin{array}{l}-0.030 \\
(0.03)\end{array}$ & .34 & $\begin{array}{l}0.015 \\
(0.07)\end{array}$ & .82 & $\begin{array}{l}0.029 \\
(0.02)\end{array}$ & N/A & $\begin{array}{l}-0.0917 \\
(0.04)\end{array}$ & .02 & $\begin{array}{l}0.036 \\
(0.10)\end{array}$ & .71 & $\begin{array}{l}-0.055 \\
(0.03)\end{array}$ & .06 \\
\hline Constant & $\begin{array}{l}2.652 \\
(0.18)\end{array}$ & $<.001$ & $\begin{array}{l}1.726 \\
(0.29)\end{array}$ & $<.001$ & $\begin{array}{l}3.042 \\
(0.14)\end{array}$ & N/A & $\begin{array}{l}2.907 \\
(0.23)\end{array}$ & $<.001$ & $\begin{array}{l}2.883 \\
(0.42)\end{array}$ & $<.001$ & $\begin{array}{l}3.212 \\
(0.18)\end{array}$ & $<.001$ \\
\hline Observations, $\mathrm{n}$ & 162 & N/A & 71 & N/A & 185 & N/A & 162 & N/A & 71 & N/A & 185 & N/A \\
\hline$R^{2}$ & 0.075 & N/A & 0.117 & N/A & 0.048 & N/A & 0.139 & N/A & 0.050 & N/A & 0.063 & N/A \\
\hline Chi-square & 13.20 & N/A & 9.47 & N/A & 9.27 & N/A & 26.18 & N/A & 3.77 & N/A & 12.43 & N/A \\
\hline $\begin{array}{l}\text { Root mean } \\
\text { square error }\end{array}$ & 0.6307 & N/A & 0.6834 & N/A & 0.4996 & N/A & 0.8166 & N/A & 0.9817 & N/A & 0.6581 & N/A \\
\hline$P$ value & N/A & .02 & N/A & .09 & N/A & .10 & N/A & $<.001$ & N/A & .58 & N/A & .03 \\
\hline
\end{tabular}

${ }^{\mathrm{a} D V}$ : dependent variable.

${ }^{\mathrm{b}}$ Standard errors in parentheses.

${ }^{\mathrm{c}} \mathrm{N} / \mathrm{A}$ : not applicable.

Table 4. Adherence seemingly unrelated regression model results for individual countries.

\begin{tabular}{|c|c|c|c|c|c|c|}
\hline \multirow[t]{2}{*}{ Variables } & \multicolumn{6}{|c|}{$\mathrm{DV}^{\mathrm{a}}$ : adherence } \\
\hline & US (1) & $P$ value & South Korea (2) & $P$ value & Kuwait (3) & $P$ value \\
\hline Threat appraisal & $0.223(0.08)^{b}$ & .006 & $0.576(0.12)$ & $<.001$ & $0.0504(0.08)$ & .55 \\
\hline Coping appraisal & $0.334(0.11)$ & .002 & $0.531(0.16)$ & .001 & $0.536(0.11)$ & $<.001$ \\
\hline Knowledge & $0.053(0.02)$ & .01 & $0.047(0.03)$ & .07 & $0.040(0.02)$ & .03 \\
\hline Age & $0.038(0.05)$ & .42 & $-0.012(0.08)$ & .88 & $-0.038(0.04)$ & .39 \\
\hline Female & $-0.025(0.14)$ & .86 & $0.202(0.17)$ & .24 & $0.043(0.12)$ & .72 \\
\hline Household income & $0.013(0.04)$ & .77 & $-0.044(0.06)$ & .49 & $-0.011(0.03)$ & .74 \\
\hline Constant & $1.644(0.45)$ & $<.001$ & $-0.135(0.39)$ & .73 & $1.968(0.52)$ & $<.001$ \\
\hline Observations, $\mathrm{n}$ & 162 & $N / A^{c}$ & 71 & N/A & 185 & N/A \\
\hline$R^{2}$ & 0.180 & N/A & 0.669 & N/A & 0.159 & N/A \\
\hline Chi-square & 35.16 & N/A & 146.67 & N/A & 33.65 & N/A \\
\hline Root mean square error & 0.8481 & N/A & 0.6629 & N/A & 0.7399 & N/A \\
\hline$P$ value & N/A & $<.001$ & N/A & $<.001$ & N/A & $<.001$ \\
\hline
\end{tabular}

${ }^{\mathrm{a} D V}$ : dependent variable.

${ }^{\mathrm{b}}$ Standard errors in parentheses.

${ }^{\mathrm{c}}$ N/A: not applicable. 
The estimated coefficients were further compared across countries using a model-based chi-square comparison test with Bonferroni adjustments, as shown in Table 5. Multimedia
Appendix 1 Table A4 further compares the coefficients across countries on the detailed PMT variables (severity, vulnerability, self-efficacy, and response efficacy).

Table 5. Comparison of coefficients across countries on the main variables.

\begin{tabular}{|c|c|c|c|c|c|c|}
\hline \multirow[t]{2}{*}{ Variables } & \multicolumn{2}{|l|}{ US vs Kuwait } & \multicolumn{2}{|c|}{ US vs South Korea } & \multicolumn{2}{|c|}{ South Korea vs Kuwait } \\
\hline & Chi-square $^{\mathrm{a}}$ & $P$ value & Chi-square & $P$ value & Chi-square & $P$ value \\
\hline \multicolumn{7}{|l|}{$D^{b}$ : threat appraisal } \\
\hline COVID-19 information sources & 0.49 & .48 & 3.19 & .07 & 1.98 & .16 \\
\hline COVID-19 social media & 5.59 & .02 & 4.98 & .03 & 1.17 & .28 \\
\hline \multicolumn{7}{|l|}{ DV: coping appraisal } \\
\hline COVID-19 information sources & 0.38 & .54 & 2.33 & .13 & 3.96 & .047 \\
\hline COVID-19 social media & 0.03 & .87 & 0.02 & .88 & 0.06 & .80 \\
\hline \multicolumn{7}{|l|}{ DV: adherence } \\
\hline Threat appraisal & 0.27 & .49 & 11.91 & $<.001$ & 12.45 & $<.001$ \\
\hline Coping appraisal & 4.47 & .049 & 1.66 & .27 & 0.25 & .62 \\
\hline Knowledge & 0.24 & .72 & 0.04 & .81 & 0.01 & .94 \\
\hline
\end{tabular}

${ }^{\mathrm{a}} \mathrm{Chi}$ square values reported with Bonferroni adjustment.

${ }^{\mathrm{b}} \mathrm{DV}$ : dependent variable.

The first set of findings examines the adherence model in Tables 2 and 4. We first examined the effect of the threat appraisal variable on adherence. As shown in Tables 2 and 4, coefficients of threat appraisal were positive and statistically significant at $P<.001$ across the full sample (Table 2 column 3), the United States $(P=.006$; Table 4 column 1$)$, and South Korea $(P<.001$; Table 4 column 2). This suggests that individuals who are threatened by the COVID-19 pandemic positively follow adherence guidance on social distancing. Further analysis of the severity coefficients in Multimedia Appendix 1 Table A3 shows positive and statistically significant influence on adherence (column 1: all sample $P<.001$; column 2: the United States $P=.03$; column 3: South Korea $P<.001$; column 4: Kuwait $P<.001)$. However, as shown in Multimedia Appendix 1 Table A3, vulnerability was not statistically significant in any of the samples. This finding shows that threat appraisal was mainly led by severity in terms of adherence to COVID-19 social distancing regulations. As displayed in Table 5, comparing the coefficients across countries, we found that the significant positive effect of threat appraisal on adherence shows that individuals who reside in the United States are more likely to follow adherence than South Korea, and those that reside in South Korea are more likely to follow adherence than those in Kuwait $(P<.001)$.

Similarly, as displayed in Multimedia Appendix 1 Table A4, comparing the coefficients across countries, we found that the significant positive effect of severity on adherence shows that individuals who reside in the United States are more likely to follow adherence than South Korea $(P=.02)$, and those in South Korea are more likely to follow adherence than those in Kuwait $(P=.046)$. As shown in Multimedia Appendix 1 Table A4, in terms of vulnerability, the positive and significant effect showed that vulnerability was more influential on adherence for individuals that reside in South Korea than Kuwait $(P=.07)$.

We subsequently examined the effect of coping appraisal on adherence. As shown in Tables 2 and 4, we found that the coefficient of coping appraisal was positive and statistically significant for all the models (Table 2 column 1: full sample, $P<.001$; Table 4 column 1: the United States, $P=.002$; Table 4 column 2: South Korea, $P=.001$; Table 4 column 3: Kuwait, $P<.001)$. Further analysis in Multimedia Appendix 1 Table A3 showed that self-efficacy was positive and statistically significant in the full model $(P=.02)$ and Kuwait only $(P=.01)$. However, response efficacy was positive and statistically significant in all the models (column 1: full sample, $P<.001$; column 2: the United States, $P<.001$; column 3: South Korea, $P<.001$; column 4: Kuwait, $P=.001)$. Interestingly, across countries, we found that, as displayed in Table 5, the significant positive impact of coping appraisal showed that those in the United States were more likely to follow adherence than those in Kuwait $(P=.049)$. In terms of self-efficacy across countries, as shown in Multimedia Appendix 1 Table A4, we found the significant positive effect of self-efficacy on adherence showed that individuals who reside in the United States and South Korea are more likely to follow adherence than those in Kuwait $(P<.001$ and $P=.04$, respectively). As for response efficacy across countries, there was no significant comparative difference in this effect, as the comparative chi-square values were not significant, as shown in Multimedia Appendix 1 Table A4.

We then examined the effect of knowledge on adherence. As shown in Tables 2 and 4, the coefficients of knowledge were positive and statistically significant (Table 2 column 3: all sample, $P<.001$; Table 4 column 1: the United States, $P=.01$; Table 4 column 3: Kuwait $P=.03$ ) on adherence except for in South Korea. As shown in Table 5, comparisons of coefficients 
for knowledge across the three countries did not show statistically significant results.

The second set of findings examined the threat appraisal model in Tables 2 and 3. As shown in Table 2 column 2, COVID-19 social media coefficients were positive and statistically significant at $P<.001$ across the full sample and the United States (Table 3 column 4 ). This suggests that social media platforms have an impact on threat appraisal. However, we found no significance for COVID-19 information sources. Comparing coefficients across countries as shown in Table 5, we found that the significant positive effect of COVID-19 social media on threat appraisal showed that individuals who reside in the United States were more likely to have higher threat appraisal than those in Kuwait $(P=.02)$ and those in South Korea $(P=.03)$.

Further analyzing the social media platform categories as shown in Multimedia Appendix 1 Table A5, in the United States, social network platforms such as Facebook and LinkedIn positively influenced threat appraisal $(P=.03)$, and text-based or microblogging platforms such as Twitter and Whatsapp positively influenced threat appraisal in the whole sample $(P<.001)$ and in the United States $(P=.007)$. Some controls of the threat appraisal model in Tables 2 and 3 were significant. Females displayed higher threat appraisal than males in the full sample and in Kuwait (Table 2 column 2: $P=.04$ and Table 3 column 6: $P=.02$, respectively). In the United States, the lower the household income, the higher the threat appraisal (Table 3 column 4: $P=.02)$.

The last set of findings examined the coping appraisal model in Tables 2 and 3. In contrast to the threat appraisal model, COVID-19 social media displayed no significance. However, coefficients for COVID-19 information sources were positive and significant for the whole sample (Table 2 column 1: $P<.001$ ), the United States (Table 3 column 1: $P=.01$ ), and South
Korea (Table 3 column 2: $P=.007$ ). This finding suggests that using more information sources has an impact on the coping appraisal. Comparing coefficients across countries as shown in Table 5, we found that the significant positive effect of COVID-19 information sources on coping appraisal showed that individuals who reside in South Korea were more likely to have higher coping appraisal than those in Kuwait $(P=.047)$.

Further analyzing the social media platform categories as shown in Multimedia Appendix 1 Table A5, social network platforms such as Facebook and LinkedIn negatively influenced coping appraisal on the whole sample $(P=.001)$, and text-based or microblogging platforms such as Twitter and Whatsapp positively influenced coping appraisal in the whole sample $(P<.001)$. Some controls of the coping appraisal model in Tables 2 and 3 were significant. Older individuals in the United States had lower coping appraisal (Table 3 column 1: $P=.01$ ). Compared to males, females had higher coping appraisal in the full model (Table 2 column 1: $P=.005$ ). Those with higher household income had higher coping appraisal in the full model (Table 2 column 1: $P=.01$ ).

\section{Discussion}

\section{Principal Findings}

In general, this study found that coping appraisal, threat appraisal, and knowledge positively influence adherence. Furthermore, using various COVID-19 information sources influences coping appraisal, and using social media for COVID-19 information influences threat appraisal. Tables 6 and 7 summarize the findings from this study (Multimedia Appendix 1 Table A6 displays the summary of findings on the specific PMT constructs and the social media platform constructs). In this section, we elaborate on the findings to provide useful policy and managerial insights.

Table 6. Summary of findings (part 1).

\begin{tabular}{|c|c|c|c|c|c|c|c|c|c|}
\hline \multirow[t]{2}{*}{ Variables } & \multicolumn{4}{|c|}{ Coping appraisal } & \multicolumn{4}{|c|}{ Threat appraisal } & \multirow[t]{2}{*}{ Findings } \\
\hline & All & US & $\begin{array}{l}\text { South } \\
\text { Korea }\end{array}$ & Kuwait & All & US & $\begin{array}{l}\text { South } \\
\text { Korea }\end{array}$ & Kuwait & \\
\hline $\begin{array}{l}\text { COVID-19 information } \\
\text { sources }\end{array}$ & $\operatorname{Pos}^{\mathrm{a}}$ & Pos & Pos & $\mathrm{NS}^{\mathrm{b}}$ & NS & NS & NS & NS & $\begin{array}{l}\mathrm{H} 1^{\mathrm{c}} \text { : Partially supported (supported for the whole } \\
\text { sample, US, and South Korea). Using more informa- } \\
\text { tion sources to get COVID-19 information positively } \\
\text { influences coping appraisal. Information sources are } \\
\text { more influential on coping appraisals in South Korea } \\
\text { than Kuwait. No comparative difference in threat } \\
\text { appraisal across countries. }\end{array}$ \\
\hline COVID-19 social media & NS & NS & NS & NS & Pos & Pos & NS & NS & $\begin{array}{l}\text { H2: Partially supported (supported for the whole } \\
\text { sample and US). Using social media to get COVID- } \\
19 \text { information positively influences threat appraisal. } \\
\text { Social media is more influential on threat appraisal } \\
\text { in US than Kuwait and South Korea. No comparative } \\
\text { difference in coping appraisal across countries. }\end{array}$ \\
\hline
\end{tabular}

\footnotetext{
${ }^{\mathrm{a} P o s:}$ positive association.

${ }^{\mathrm{b}} \mathrm{NS}$ : not significant.

${ }^{\mathrm{c}} \mathrm{H}$ : hypothesis.
} 
Table 7. Summary of findings (part 2).

\begin{tabular}{|c|c|c|c|c|c|}
\hline \multirow[t]{2}{*}{ Variables } & \multicolumn{4}{|c|}{ Adherence } & \multirow[t]{2}{*}{ Findings } \\
\hline & All & US & South Korea & Kuwait & \\
\hline Threat appraisal & $\operatorname{Pos}^{\mathrm{a}}$ & Pos & Pos & $\mathrm{NS}^{\mathrm{b}}$ & $\begin{array}{l}\mathrm{H} 3^{\mathrm{c}} \text { : Partially supported (supported for the whole sample, US, } \\
\text { and South Korea). Threat appraisal positively influences social } \\
\text { distancing adherence. Threat appraisal is more influential in US } \\
\text { than in South Korea, and more in South Korea than in Kuwait. }\end{array}$ \\
\hline Coping appraisal & Pos & Pos & Pos & Pos & $\begin{array}{l}\text { H4: Supported. Coping appraisal positively influences social } \\
\text { distancing adherence. Coping is more influential in US than } \\
\text { Kuwait in terms of adherence. }\end{array}$ \\
\hline Knowledge & Pos & Pos & NS & Pos & $\begin{array}{l}\text { Knowledge positively influences social distancing adherence in } \\
\text { the whole sample, US, and Kuwait. No comparative difference } \\
\text { in results across countries. }\end{array}$ \\
\hline
\end{tabular}

apos: positive association.

${ }^{\mathrm{b}} \mathrm{NS}$ : not significant.

${ }^{\mathrm{c}} \mathrm{H}$ : hypothesis.

First, the study found that using more information sources positively influences the coping appraisal associated with the COVID-19 pandemic situation. Undoubtedly, this finding's importance relates to the increasing use and trade-off of information sources by the public. As much as people like to use many information sources, whether it is beneficial or not remains a question. Furthermore, citizens may be swayed by popular information sources such as the internet, TV, and newspapers. This finding highlights the benefits of using multiple information sources during the COVID-19 pandemic. This could be due to the high amount of misinformation and that the pandemic is ever-evolving. Therefore, attaining multiple information sources allows individuals to obtain more accurate information that helps with their coping appraisal. This finding is in line with a recent COVID-19 study that displayed an association between more sources of information and higher self-confidence to cope with COVID-19 in health care workers, yet the direction of the association was not confirmed in their study [22]. Thus, this study sheds light on this literature and displays the importance of multiple sources of information to cope with the COVID-19 pandemic [48]. The study also found that information sources are more influential on the coping appraisal in South Korea than Kuwait, displaying that individuals in South Korea are more rationally using information sources to cope than individuals in Kuwait.

Second, this study found that using social media to get COVID-19 information positively influences threat appraisal. This is an important finding to validate the increasing trustworthiness of social media on people's decisions and the role of social media in this pandemic. Social media is one of the main channels used to provide updated COVID-19 information [49]. This study's findings are consistent with previous studies [50] that showed that the frequency of social media was associated with high odds of anxiety [51]. This association might be because, throughout the COVID-19 pandemic, many false reports and misinformation bombarded social media, which resulted in a lot of confusion and anxiety [50]. Furthermore, many individuals use social media to express their feelings of worry, anxiety, nervousness, and fear, which is contagious in social networks [52]. As we stated earlier, the social media role in people's minds during the pandemic is not free from harmful aspects such as increased anxiety, sleep disturbance, suicidal thoughts[19], misinformation, and distress $[20,21]$. Thus, it is interesting to note the positive aspects such as social media's role in adherence decisions. As for country comparisons, we found that social media is more influential on threat appraisal in the United States than in South Korea and Kuwait. A possible reason for this finding is that social media information in the United States might be more fearful or driven with more riddles (ie, whether to trust Twitter postings or not) compared to South Korea and Kuwait.

Third, threat appraisal positively influences social distancing adherence. One of the primary emotional responses during a pandemic is fear [53]. This fear is a defensive system to combat ecological threats [54]. A meta-analysis found that targeting fears can be useful in situations, such that appealing to fear leads people to change their behavior if they feel capable of dealing with the threat but leads to defensive reactions when they feel helpless to act [55]. This study sheds light on this stream of research by displaying that fear or threat appraisal was useful in the COVID-19 pandemic since it changes an individual's behavior and influences their social distancing adherence.

Based on PMT, a fear appeal is a cognitive assessment that prepares individuals against the severity of a threatening event. People consider the pros and cons, and the probability of the event occurring to develop a response. The recommended response in the COVID-19 context is adherence. The cognitive assessment enhances the fear appeal and subsequent motivation to protect oneself-without which the recommended action would not be effective across citizens. Besides, there is a more substantial threat appraisal for social distance adherence in the United States than in South Korea and Kuwait. This follows through with the social media country comparison finding; in addition, the finding shows that threat appraisal in the United States is more rational than that of South Korea and Kuwait.

Fourth, coping appraisal positively influences social distancing adherence, and this effect is more influential in the United States than Kuwait, again displaying that individuals in the United States are more pragmatic in the coping and adherence process. 
One of the main factors that have been stressed upon during the COVID-19 pandemic is how to cope with the current situation [15]. Studies have shown that problem-focused coping is associated with better adherence to health-related behaviors and a higher sense of control [56,57]. The findings support these perspectives and suggest, as per PMT, that the preventive actions will be preferred in a high threat situation when both the self-efficacy and the efficacy of the adherence plans are high. This finding agrees with this research stream and displays the importance of coping appraisal during the COVID-19 pandemic to adhere to social distancing recommendations.

These findings partially explain the variations observed in the adherence outcomes, which can be explained due to the variations observed in the threat and coping appraisals. Finally, as an additional outcome, we found that knowledge positively influences social distancing adherence in the whole sample, the United States, and Kuwait. There were no comparative difference in results across countries. This sheds light on the importance of correct knowledge during this pandemic to be able to adhere to social distancing recommendations. Association between adherence and better knowledge of the disease is consistent with recent findings and provides evidence for using proper interventions of proper communication related to the disease on improving adherence $[56,58]$.

\section{Practice and Policy Implications}

A set of implications and recommendations for public health officials and policy makers can be drawn from this study. This study points to the gap in the responsible behavior of individuals regarding adherence. The current government efforts to mitigate and the expectation that everything should be back to normal have differing consequences. Existing work suggests that policy recommendations' efficacy and outcomes depend on the individuals' beliefs and subsequent actions [59,60]. The first step in this process is the firm belief of whether the recommended action will mitigate the threat or manage the fearful situation.

Thus, the key to minimizing rejection and maximizing acceptance of recommendation is reliant on the messages and information provided to citizens. Often, the media outlets and information sources are left to craft their messages independently or freely without the policy makers' recommended guidelines. There needs to be policy guidelines with careful attention about what messages to give and how to give them, so that it does not instill too much fear nor allow citizens to be too careless (ie, messages and information need to have a balance to involve appropriate threat and coping appraisals in citizens' minds).

\section{Limitations}

This study examines factors that influence citizens adhering to social distancing at a point in time. However, the citizen might go back and forth in the adherence process, and the threat appraisal, coping appraisal, knowledge level, and sources of information may change over time. This is a limitation of this study, as the data set used is a cross-sectional survey. Future studies could examine how a citizen's coping appraisal, threat appraisal, and adherence changes over time.

In addition, using the random sampling process in the United States, Kuwait, and South Korea samples may include fewer familiar respondents to the study context. In particular, the questionnaire was only online. Therefore, respondents were all users of the internet. The study does not examine noninternet users, which could have differential impacts. Thus, the generalization of the sample to a uniform national culture characteristic is a limitation of this study. Future studies could conduct online and offline surveys, and examine the difference in threat and coping appraisal in terms of adherence behavior.

The findings should be taken with care due to the sample being representative of three countries; thus, future studies could expand to more countries to examine even more cultural differences. Another limitation is the small sample size for South Korea, limiting the generalizability of the results.

\section{Conclusions}

As the COVID-19 global pandemic continues to grow and governmental restrictions are ongoing, it is critical to understand people's frustration to reduce panic and promote social distancing to control the pandemic. This study points to a threat and coping appraisal mechanism that may clarify the adherence variations. This study also highlights that social media has an impact on the threat appraisal of the COVID-19 pandemic. Furthermore, the intensity of information sources used to attain COVID-19 information impacts the coping appraisal for the pandemic.

\section{Conflicts of Interest}

None declared.

\section{Multimedia Appendix 1}

Survey questionnaire and detailed analysis.

[DOCX File, 129 KB-Multimedia Appendix 1]

\section{References}

1. COVID-19 dashboard by the Center for Systems Science and Engineering (CSSE) at Johns Hopkins University (JHU). Johns Hopkins University. URL: https://coronavirus.jhu.edu/map.html [accessed 2020-05-01]

2. Coronavirus disease (COVID-19). World Health Organization. 2020. URL: https://www.who.int/news-room/q-a-detail/ q-a-coronaviruses [accessed 2020-05-10] 
3. Bai Y, Yao L, Wei T, Tian F, Jin D, Chen L, et al. Presumed asymptomatic carrier transmission of COVID-19. JAMA 2020 Apr 14;323(14):1406-1407 [FREE Full text] [doi: 10.1001/jama.2020.2565] [Medline: 32083643]

4. Guan W, Ni Z, Hu Y, Liang W, Ou C, He J, China Medical Treatment Expert Group for Covid-19. Clinical characteristics of coronavirus disease 2019 in China. N Engl J Med 2020 Apr 30;382(18):1708-1720 [FREE Full text] [doi: 10.1056/NEJMoa2002032] [Medline: 32109013]

5. Prompetchara E, Ketloy C, Palaga T. Immune responses in COVID-19 and potential vaccines: lessons learned from SARS and MERS epidemic. Asian Pac J Allergy Immunol 2020 Mar;38(1):1-9 [FREE Full text] [doi: 10.12932/AP-200220-0772] [Medline: 32105090]

6. Fisher D, Heymann D. BMC Med 2020 Feb 28;18(1):57 [FREE Full text] [doi: 10.1186/s12916-020-01533-w] [Medline: 32106852]

7. Ahorsu DK, Imani V, Lin C, Timpka T, Broström A, Updegraff JA, et al. Associations between fear of COVID-19, mental health, and preventive behaviours across pregnant women and husbands: an actor-partner interdependence modelling. Int J Ment Health Addict 2020 Jun 11:1-15 [FREE Full text] [doi: 10.1007/s11469-020-00340-x] [Medline: 32837427]

8. Chang K, Strong C, Pakpour AH, Griffiths MD, Lin C. Factors related to preventive COVID-19 infection behaviors among people with mental illness. J Formos Med Assoc 2020 Jul 29:S0929-6646(20)30344-2 [FREE Full text] [doi: 10.1016/j.jfma.2020.07.032] [Medline: 32773260]

9. Lin C, Imani V, Majd NR, Ghasemi Z, Griffiths MD, Hamilton K, et al. Using an integrated social cognition model to predict COVID-19 preventive behaviours. Br J Health Psychol 2020 Nov;25(4):981-1005 [FREE Full text] [doi: 10.1111/bjhp.12465] [Medline: 32780891]

10. Lin M, Cheng Y. Policy actions to alleviate psychosocial impacts of COVID-19 pandemic: experiences from Taiwan. Soc Health Behav 2020;3(2):72. [doi: 10.4103/shb.shb 18 20]

11. Usman N, Mamun M, Ullah I. COVID-19 infection risk in pakistani health-care workers: the cost-effective safety measures for developing countries. Soc Health Behav 2020;3(3):75. [doi: 10.4103/shb.shb 26 20]

12. Sohrabi C, Alsafi Z, O'Neill N, Khan M, Kerwan A, Al-Jabir A, et al. World Health Organization declares global emergency: a review of the 2019 novel coronavirus (COVID-19). Int J Surg 2020 Apr;76:71-76 [FREE Full text] [doi: 10.1016/j.ijsu.2020.02.034] [Medline: 32112977]

13. Rieger M. To wear or not to wear? Factors influencing wearing face masks in Germany during the COVID-19 pandemic. Soc Health Behav 2020;3(2):50. [doi: 10.4103/shb.shb_23_20]

14. Rieger M. Triggering altruism increases the willingness to get vaccinated against COVID-19. Soc Health Behav 2020;3(3):78. [doi: $10.4103 /$ shb.shb 39 20]

15. Stress and coping. Centers for Disease Control and Prevention. 2020. URL: https://www.cdc.gov/coronavirus/2019-ncov/ daily-life-coping/stress-coping/index.html [accessed 2020-06-08]

16. Satici B, Gocet-Tekin E, Deniz ME, Satici SA. Adaptation of the fear of COVID-19 scale: its association with psychological distress and life satisfaction in Turkey. Int J Ment Health Addict 2020 May 08:1-9 [FREE Full text] [doi: 10.1007/s11469-020-00294-0] [Medline: 32395095]

17. Montemurro N. The emotional impact of COVID-19: from medical staff to common people. Brain Behav Immun 2020 Jul;87:23-24 [FREE Full text] [doi: 10.1016/j.bbi.2020.03.032] [Medline: 32240766]

18. Lin C. Social reaction toward the 2019 novel coronavirus (COVID-19). Soc Health Behav 2020;3(1):1. [doi: $10.4103 /$ shb.shb 1120$]$

19. Li D, Ko N, Chen Y, Wang P, Chang Y, Yen C, et al. COVID-19-related factors associated with sleep disturbance and suicidal thoughts among the Taiwanese public: a Facebook survey. Int J Environ Res Public Health 2020 Jun 22;17(12):4479 [FREE Full text] [doi: 10.3390/ijerph17124479] [Medline: 32580433]

20. Olatunji O, Ayandele O, Ashirudeen D, Olaniru O. "Infodemic" in a pandemic: COVID-19 conspiracy theories in an african country. Soc Health Behav 2020;3(4):152. [doi: 10.4103/shb.shb 43 20]

21. Lin C, Broström A, Griffiths MD, Pakpour AH. Investigating mediated effects of fear of COVID-19 and COVID-19 misunderstanding in the association between problematic social media use, psychological distress, and insomnia. Internet Interv $2020 \mathrm{Sep} ; 21: 100345$ [FREE Full text] [doi: 10.1016/j.invent.2020.100345] [Medline: 32868992]

22. Wang P, Lu W, Ko N, Chen Y, Li D, Chang Y, et al. COVID-19-related information sources and the relationship with confidence in people coping with COVID-19: Facebook survey study in Taiwan. J Med Internet Res 2020 Jun 05;22(6):e20021 [FREE Full text] [doi: 10.2196/20021] [Medline: $\underline{\text { 32490839] }}$

23. Farooq A, Laato S, Islam AKMN. Impact of online information on self-isolation intention during the COVID-19 pandemic: cross-sectional study. J Med Internet Res 2020 May 06;22(5):e19128 [FREE Full text] [doi: 10.2196/19128] [Medline: 32330115]

24. Ornell F, Schuch JB, Sordi AO, Kessler FHP. "Pandemic fear" and COVID-19: mental health burden and strategies. Braz J Psychiatry 2020;42(3):232-235 [FREE Full text] [doi: 10.1590/1516-4446-2020-0008] [Medline: 32267343]

25. Aronson E, Akert RM, Wilson TD. Sozialpsychologie. Hallbergmoos, Germany: Pearson Deutschland GmbH; 2010.

26. Baron RS, Vandello JA, Brunsman B. The forgotten variable in conformity research: impact of task importance on social influence. J Pers Soc Psychol 1996;71(5):915-927. [doi: 10.1037/0022-3514.71.5.915] 
27. Lucas T, Alexander S, Firestone IJ, Baltes BB. Self - efficacy and independence from social influence: discovery of an efficacy-difficulty effect. Soc Influence 2006 Mar;1(1):58-80. [doi: 10.1080/15534510500291662]

28. Cialdini RB, Goldstein NJ. Social influence: compliance and conformity. Annu Rev Psychol 2004;55:591-621. [doi: 10.1146/annurev.psych.55.090902.142015] [Medline: 14744228]

29. Bhagavathula AS, Aldhaleei WA, Rahmani J, Mahabadi MA, Bandari DK. Knowledge and perceptions of COVID-19 among health care workers: cross-sectional study. JMIR Public Health Surveill 2020 Apr 30;6(2):e19160 [FREE Full text] [doi: 10.2196/19160] [Medline: 32320381]

30. Hernández-García I, Giménez-Júlvez T. Assessment of health information about COVID-19 prevention on the internet: infodemiological study. JMIR Public Health Surveill 2020 Apr 01;6(2):e18717 [FREE Full text] [doi: 10.2196/18717] [Medline: 32217507]

31. Li C, Chen LJ, Chen X, Zhang M, Pang CP, Chen H. Retrospective analysis of the possibility of predicting the COVID-19 outbreak from internet searches and social media data, China, 2020. Euro Surveill 2020 Mar;25(10):2000199 [FREE Full text] [doi: 10.2807/1560-7917.ES.2020.25.10.2000199] [Medline: 32183935]

32. Bish A, Michie S. Demographic and attitudinal determinants of protective behaviours during a pandemic: a review. Br $\mathbf{J}$ Health Psychol 2010 Nov;15(Pt 4):797-824 [FREE Full text] [doi: 10.1348/135910710X485826] [Medline: 20109274]

33. Timpka T, Spreco A, Gursky E, Eriksson O, Dahlström Ö, Strömgren M, et al. Intentions to perform non-pharmaceutical protective behaviors during influenza outbreaks in Sweden: a cross-sectional study following a mass vaccination campaign. PLoS One 2014;9(3):e91060 [FREE Full text] [doi: 10.1371/journal.pone.0091060] [Medline: 24608557]

34. Floyd DL, Prentice-Dunn S, Rogers RW. A meta-analysis of research on protection motivation theory. J Appl Social Pyschol 2000 Feb;30(2):407-429. [doi: 10.1111/j.1559-1816.2000.tb02323.x]

35. Milne S, Sheeran P, Orbell S. Prediction and intervention in health-related behavior: a meta-analytic review of protection motivation theory. J Appl Social Pyschol 2000 Jan;30(1):106-143. [doi: 10.1111/j.1559-1816.2000.tb02308.x]

36. Lee SA. Coronavirus Anxiety Scale: a brief mental health screener for COVID-19 related anxiety. Death Stud 2020;44(7):393-401. [doi: 10.1080/07481187.2020.1748481] [Medline: 32299304]

37. Lee SA. How much "Thinking" about COVID-19 is clinically dysfunctional? Brain Behav Immun 2020 Jul;87:97-98 [FREE Full text] [doi: $\underline{10.1016 / j . b b i .2020 .04 .067]}$ [Medline: $\underline{32353520]}$

38. Ahorsu DK, Lin C, Imani V, Saffari M, Griffiths MD, Pakpour AH. The fear of COVID-19 scale: development and initial validation. Int J Ment Health Addict 2020 Mar 27:1-9 [FREE Full text] [doi: 10.1007/s11469-020-00270-8] [Medline: $\underline{32226353}$ ]

39. Chang K, Hou W, Pakpour AH, Lin C, Griffiths MD. Psychometric testing of three COVID-19-related scales among people with mental illness. Int J Ment Health Addict 2020 Jul 11:1-13 [FREE Full text] [doi: 10.1007/s11469-020-00361-6] [Medline: 32837442]

40. Rahaei Z, Ghofranipour F, Morowatisharifabad MA, Mohammadi E. Psychometric properties of a protection motivation theory questionnaire used for cancer early detection. J Sch Public Health Institute Public Health Res 2015;12(3):69-79.

41. Xiao H, Li S, Chen X, Yu B, Gao M, Yan H, et al. Protection motivation theory in predicting intention to engage in protective behaviors against schistosomiasis among middle school students in rural China. PLoS Negl Trop Dis 2014 Oct;8(10):e3246 [FREE Full text] [doi: 10.1371/journal.pntd.0003246] [Medline: 25329829]

42. Yan Y, Jacques-Tiura AJ, Chen X, Xie N, Chen J, Yang N, et al. Application of the protection motivation theory in predicting cigarette smoking among adolescents in China. Addict Behav 2014 Jan;39(1):181-188 [FREE Full text] [doi: 10.1016/j.addbeh.2013.09.027] [Medline: 24157424]

43. Macdonell K, Chen X, Yan Y, Li F, Gong J, Sun H, et al. A protection motivation theory-based scale for tobacco research among Chinese youth. J Addict Res Ther 2013 Jul 08;4:154 [FREE Full text] [doi: 10.4172/2155-6105.1000154] [Medline: 24478933]

44. Hassani L, Dehdari T, Hajizadeh E, Shojaeizadeh D, Abedini M, Nedjat S. Development of an instrument based on the protection motivation theory to measure factors influencing women's intention to first pap test practice. Asian Pac J Cancer Prev 2014;15(3):1227-1232 [FREE Full text] [doi: 10.7314/apjcp.2014.15.3.1227] [Medline: 24606445]

45. Xiao H, Peng M, Yan H, Gao M, Li J, Yu B, et al. An instrument based on protection motivation theory to predict Chinese adolescents' intention to engage in protective behaviors against schistosomiasis. Glob Health Res Policy 2016;1:15 [FREE Full text] [doi: 10.1186/s41256-016-0015-6] [Medline: 29202064]

46. Rogers RW. A protection motivation theory of fear appeals and attitude change1. J Psychol 1975 Sep;91(1):93-114. [doi: 10.1080/00223980.1975.9915803] [Medline: 28136248]

47. Frequently asked questions. Centers for Disease Control and Prevention. 2020. URL: https://www.cdc.gov/coronavirus/ 2019-ncov/faq.html?CDC AA refVal=https\%3A\%2F\%2Fwww.cdc. gov\%2Fcoronavirus\%2F2019-ncov\%2Fprepare\%2Fchildren-faq.html [accessed 2020-05-02]

48. Al-Hasan A, Yim D, Khuntia J. Citizens' adherence to COVID-19 mitigation recommendations by the government: a three-country comparative evaluation using online cross-sectional survey data. J Med Internet Res 2020 Aug 11;22(8):e20634 [FREE Full text] [doi: 10.2196/20634] [Medline: 32716896]

49. Bao Y, Sun Y, Meng S, Shi J, Lu L. 2019-nCoV epidemic: address mental health care to empower society. Lancet 2020 Feb 22;395(10224):e37-e38 [FREE Full text] [doi: 10.1016/S0140-6736(20)30309-3] [Medline: 32043982] 
50. Gao J, Zheng P, Jia Y, Chen H, Mao Y, Chen S, et al. Mental health problems and social media exposure during COVID-19 outbreak. PLoS One 2020;15(4):e0231924 [FREE Full text] [doi: 10.1371/journal.pone.0231924] [Medline: $\underline{\text { 32298385] }}$

51. Neria Y, Sullivan GM. Understanding the mental health effects of indirect exposure to mass trauma through the media. JAMA 2011 Sep 28;306(12):1374-1375 [FREE Full text] [doi: 10.1001/jama.2011.1358] [Medline: 21903818]

52. Kramer ADI, Guillory JE, Hancock JT. Experimental evidence of massive-scale emotional contagion through social networks. Proc Natl Acad Sci U S A 2014 Jun 17;111(24):8788-8790 [FREE Full text] [doi: 10.1073/pnas.1320040111] [Medline: 24889601]

53. Bavel JJV, Baicker K, Boggio PS, Capraro V, Cichocka A, Cikara M, et al. Using social and behavioural science to support COVID-19 pandemic response. Nat Hum Behav 2020 May;4(5):460-471. [doi: 10.1038/s41562-020-0884-z] [Medline: 32355299]

54. Mobbs D, Hagan CC, Dalgleish T, Silston B, Prévost C. The ecology of human fear: survival optimization and the nervous system. Front Neurosci 2015;9:55. [doi: 10.3389/fnins.2015.00055] [Medline: 25852451]

55. Witte K, Allen M. A meta-analysis of fear appeals: implications for effective public health campaigns. Health Educ Behav 2000 Oct;27(5):591-615. [doi: 10.1177/109019810002700506] [Medline: 11009129]

56. Vélez-Vélez E, Bosch RJ. Illness perception, coping and adherence to treatment among patients with chronic kidney disease. J Adv Nurs 2016 Apr;72(4):849-863. [doi: 10.1111/jan.12873] [Medline: 26689295]

57. Ransom S, Jacobsen PB, Schmidt JE, Andrykowski MA. Relationship of problem-focused coping strategies to changes in quality of life following treatment for early stage breast cancer. J Pain Symptom Manage 2005 Sep;30(3):243-253 [FREE Full text] [doi: 10.1016/j.jpainsymman.2005.03.013] [Medline: 16183008 ]

58. Parvan K, Hasankhani H, Seyyedrasooli A, Riahi SM, Ghorbani M. The effect of two educational methods on knowledge and adherence to treatment in hemodialysis patients: clinical trial. J Caring Sci 2015 Mar;4(1):83-93 [FREE Full text] [doi: 10.5681/jcs.2015.009] [Medline: 25821762]

59. Mukhtar S. Mental health and emotional impact of COVID-19: applying Health Belief Model for medical staff to general public of Pakistan. Brain Behav Immun 2020 Jul;87:28-29 [FREE Full text] [doi: 10.1016/j.bbi.2020.04.012] [Medline: 32283289]

60. Guidry JPD, Carlyle KE, LaRose JG, Perrin P, Messner M, Ryan M. Using the Health Belief Model to analyze Instagram posts about Zika for public health communications. Emerg Infect Dis 2019 Jan;25(1):179-180. [doi: 10.3201/eid2501.180824] [Medline: 30561302]

\section{Abbreviations \\ PMT: protection motivation theory \\ SUR: seemingly unrelated regression}

Edited by $G$ Eysenbach; submitted 29.07.20; peer-reviewed by CF Yen, K Aguirre, CY Lin; comments to author $17.10 .20 ;$ revised
version received 27.10.20; accepted 28.10.20; published 18.11 .20
Please cite as:
Al-Hasan A, Khuntia J, Yim D
Threat, Coping, and Social Distance Adherence During COVID-19: Cross-Continental Comparison Using an Online Cross-Sectional
Survey
J Med Internet Res 2020;22(11):e23019
URL: $\underline{\text { http://www.jmir.org/2020/11/e23019/ }}$
doi: $\underline{10.2196 / 23019}$
PMID: $\underline{33119538}$

(C)Abrar Al-Hasan, Jiban Khuntia, Dobin Yim. Originally published in the Journal of Medical Internet Research (http://www.jmir.org), 18.11.2020. This is an open-access article distributed under the terms of the Creative Commons Attribution License (https://creativecommons.org/licenses/by/4.0/), which permits unrestricted use, distribution, and reproduction in any medium, provided the original work, first published in the Journal of Medical Internet Research, is properly cited. The complete bibliographic information, a link to the original publication on http://www.jmir.org/, as well as this copyright and license information must be included. 